\title{
Climate Change Projections and the Associated Potential Impacts for Somalia
}

\author{
Linda Ajuang Ogallo', Philip Omondi², Gilbert Ouma1, Gordon Wayumba ${ }^{3}$ \\ ${ }^{1}$ Institute of Climate Change and Adaptation, University of Nairobi, Nairobi, Kenya \\ ${ }^{2}$ IGAD Climate Prediction and Application Centre, Nairobi, Kenya \\ ${ }^{3}$ The Technical University of Kenya, Nairobi, Kenya \\ Email: lindaogallo@gmail.com
}

How to cite this paper: Ogallo, L.A., Omondi, P., Ouma, G. and Wayumba, G. (2018) Climate Change Projections and the Associated Potential Impacts for Somalia. American Journal of Climate Change, 7 , 153-170.

https://doi.org/10.4236/ajcc.2018.72011

Received: March 2, 2018

Accepted: May 15, 2018

Published: May 18, 2018

Copyright $(0) 2018$ by authors and Scientific Research Publishing Inc. This work is licensed under the Creative Commons Attribution International License (CC BY 4.0).

http://creativecommons.org/licenses/by/4.0/

\section{(c) (i) Open Access}

\begin{abstract}
Somalia has faced severe challenges linked to climate variability, which has been exacerbated by conflict and limited governance that persisted for decades. Today climate extremes such as floods, drought, and coastal marine severe systems among others are always associated with the destruction of property and livelihoods; losses of lives lost, migrations, and resource based conflicts among many other miseries. Intergovernmental Panel on Climate Change (IPCC) has shown that climate change is real and requires sound knowledge of local future climate change scenarios. The study attempted to provide projected rainfall and temperature change scenarios over Lower Jubba, Somalia. This was done using the downscaled Coordinated Regional Downscaling Experiment (CORDEX) RCMs data. The simulated temperature and rainfall data derived from the CORDEX RCMs ensemble were compared with the observed data. The study focused on the IPCC projected periods of 2030, 2050 and 2070 benchmarks. Analysis of the projected rainfall indicated a decreasing trend in rainfall leading up to 2030 followed by an increase in rainfall with the 2050 and 2070 scenarios. In the case of temperature, the projections from all the models showed increase in minimum and maximum temperatures in all seasons and sub periods, like being observed by temperature projection over other parts of the world. The 2030, 2050 and 2070 projected rainfall and temperature change scenarios show that Somalia future development and livelihoods will in future face increased threats of climate extremes unless effective climate smart adaptation systems form integral components of national development strategies.
\end{abstract}

\section{Keywords}

Climate Change, Climate Modeling, Somalia, Projections, CORDEX 


\section{Introduction}

Increasing evidence is able to link climate change to major and minor threats to natural systems, threatening environmental, social and economic development [1] [2]. In Sub-Saharan Africa, vulnerability to climate change for local communities is increased because of their dependence on rain fed agriculture [3] [4] [5] [6]. Large populations in Somalia in particular have experienced severer impacts due to water stress as their livelihoods are dependent on access to water and pasture [7] [8]. 94\% of nomadic populations in Somalia are reportedly living in poverty. Somalia's long coastal line provides fishing livelihood systems threatened by unique marine systems that include Somalia ocean currents systems, tropical cyclones and before tropical cyclones.

Somalia has seen an increase in frequency and intensity of floods and droughts with severe droughts in 2007/2008, 2011/2012, 2015/16/17 [9]. Climate induced displacement in Somalia continues to increase with UN listing the number of internally displaced persons due to drought between November 2016 and October 2017 at 943,000 [10]. Sendai Framework for Disaster Risk Reduction (2015-2030) recognized the difficulty in achieving sustainable development without the development of climate smart systems. Climate change impacts are projected to slow down economic growth, making poverty reduction even more difficult, while prolonging existing poverty traps [2].

Climate change risks undermine the sustainability of basic livelihoods, threatening food security, health among other socio-economic impacts. Without proper adaptation measures, the projected increase in frequency and severity of weather and climate extremes will undermine the safety of ecosystems and health [11] [12] [13] [14] [15]. The need to strengthen Somalia's capacity to deal with disasters, such as the protracted droughts and floods that it continues to face, is critical [16].

The study attempted to provide projected rainfall and temperature change scenarios for Lower Jubba region, Somalia. This was done using the downscaled Coordinated Regional Downscaling Experiment (CORDEX) RCMs data. The annual rainfall and temperature cycles simulated by an ensemble of CORDEX RCMs were compared with the observed data. The analysis focused on the $\mathrm{Gu}$ long rain season, which had the best agreement in comparison to the observed rainfall data. Projections for temperature were done for all the standard global climatological seasons namely northern hemisphere summer, winter, autumn and spring seasons that correspond to June to August, December to February, September to November, March to May months. The projections of the future $\mathrm{Gu}$ long rain season characteristics was done using the IPCC projected periods of 2030, 2050 and 2070 benchmarks. Lower Jubba is located in the Jubaland state of Somalia [17] [18]. Jubaland consists of the Gedo, Lower Jubba and Middle Jubba regions, and lies 40 - $60 \mathrm{~km}$ east of the Jubba River, stretching from Gedo to the Indian Ocean. The state of Jubaland borders the Garrisa, Wajir and Mandera County of Kenya on the western side. Kismayo, located in Lower Jubba, is 
the largest city in Jubaland, and the third largest city in Somalia after Mogadishu and Hargesa [19].

Lower Jubba receives about $350 \mathrm{~mm}$ rainfall during $\mathrm{Gu}$ (AMJ) season and an average of $250 \mathrm{~mm}$ Deyr (SON) season. Lower Jubba saw a general decreasing trend in rainfall during the $\mathrm{Gu}$ rainfall season, and a general increasing trend in the Deyr rainfall between 1981 to 2015 [20]. The Lower Jubba region has also experienced an increase in occurrence of depressed rainfall usually associated with drought, and a decrease in the frequency of above normal rainfall associated with floods [20]. Studies on the GHA show a decrease of MAM long rains and increase in the OND short rains [21] [22] [23].

Lower Jubba has seen increasing trends in the minimum, maximum and average temperature [20], consistent with the results from many recent studies worldwide [2] [24] [25]. Increase in temperature could also change the ecology of infectious diseases as well as increase temperature related mortality and morbidity of people and livestock [2] [26] [27].

Climate Change projections for Somalia will be used to derive information regarding the potential increase of the threats of climate extremes on future development and livelihoods. It will also enable the development of effective climate smart adaptation strategies. Details of area of study, data used and methodologies adopted are highlighted in the following sections.

\section{Study Area, and Data Used}

Gridded CHIRPS and GeoCLIM observations for the period 1960-90 were used as the baseline observations data. CHIRPS is a global dataset $\left(50^{\circ} \mathrm{S}-50^{\circ} \mathrm{N}, 180^{\circ} \mathrm{E}\right.$ - $\left.180^{\circ} \mathrm{W}\right), 0.05^{\circ}$ resolution, 1981 to near-present gridded precipitation time series. CHIRPS data are produced by scientists at the University of California, Santa Barbara (UCSB) Climate Hazard Group (CHG) and the U.S. Geological Survey (USGS) Earth Resources Observation and Science (EROS) Center. The data was developed to support the United States Agency for International Development Famine Early Warning Systems Network (FEWS NET). Rainfall Measuring Mission Multi-satellite Precipitation Analysis version 7 (TMPA 3B42 v7) is used to calibrate global Cold Cloud Duration (CCD) rainfall estimates. Details on CHIRPS data and their usability in the region are well documented by ICPAC among many others [28] [29].

A coordinated set of the 20th and 21st century climate simulations for the Atmosphere Ocean coupled Global Climate Models (AOGCMs) in the Coupled Model Inter-comparison Project phase 5 (CMIP5) have been contributed to by climate modelling groups from all around the world [30]. Data from the Coordinated Regional Climate Downscaling Experiment (CORDEX) Africa framework was used in this study to project scenarios for precipitation in Lower Jubba. The CORDEX program is an initiative by World Climate Research Program (WCRP) of the World Meteorological Organization (WMO) that generates high-resolution climate projections $(50 \mathrm{~km})$ for climate studies, within the Intergovernmental Panel on Climate Change (IPCC) Fifth Assessment Report 
(AR5) timeline and beyond [31] [32] [33]. CORDEX data used in this study represented precipitation fairly well over the region and thus can be used to inform on adaptation and mitigation strategies [32] [33] [34] [35] [36].

These climate models describe the coupling of the atmosphere with the land surface, with differing dynamics and physics formulations [31] [37]. For each experiment the historical runs, forced by observed natural and anthropogenic atmospheric composition, cover the period from 1950-2005. The future projections (2006-2100) are forced with two Representative Concentration Pathways (RCP), namely; RCP4.5 (mid-range emissions) and RCP8.5 (high-end emissions) scenarios, which prescribe future atmospheric greenhouse gas concentrations and aerosols. Detail on the CORDEX RCMs can be found in Endris [32] and Nikulin [33].

Endris [32] evaluated the ability of the CORDEX RCMs in simulating the general characteristics of the climate over Eastern Africa region by analyzing the annual cycle, spatial variability, pattern correlation and root mean square error using a Taylor diagram. The study found that these RCMs reasonably simulate the main features of the rainfall climatology over eastern Africa and also reproduce the majority of the documented regional responses to ENSO and IOD forcings. At the same time the analysis showed significant biases in individual models depending on sub-region and season; however, the ensemble mean had better agreement with observation than individual models. The analysis concluded that the multi-model ensemble mean simulates eastern Africa rainfall adequately and could therefore be used for the assessment of future climate projections for the region. The CORDEX RCMs data was obtained from IGAD Climate Prediction and Application Centre (ICPAC) which is the WMO regional climate center for the Greater Horn of Africa.

In this study the region of interest was Lower Jubba that is bounded by latitudes $1.5^{\circ} \mathrm{S}-12.0^{\circ} \mathrm{N}$ and longitudes $41.0^{\circ} \mathrm{E}-51.0^{\circ} \mathrm{E}$. There IPCC based climate projection reference period were used namely 2030 (sub-period 1), sub-period up to 2050 (sub-period 2), and sub-period up to 2070 (sub-period 3).

\section{Methodology Adopted in the Study}

The study was divided into two major sections namely assessment of Model Skill in Simulating Observed Climate during the period 1961-1990, and the projection of future rainfall and temperature scenarios. Standard methods were adopted to determine the best climate model/s that could be used for the projection of future climate change scenarios for Lower Jubba region of Somalia for the two standard rainfall seasons Gu (April to June) and Deyr (September to November). The temperature simulations were for all standard seasons of the year in Somalia namely December-February (DJF), March-May (MAM), July-August (JJA), and September-November (SON).

Standard methods were also adopted to test the spatial and temporal bias of the individual models. The methods used included various time series methods, correlation and regression analysis. Correlation methods examined correlations 
between the observed and simulated outputs at specific grid point locations. The square of the correlation coefficient is knows as coefficient of determination (r2) which represented the variance of the observed data that could be accounted for by the predicted variable.

Regression method attempted to fit the best linear mathematical equation for the observed relationships. The statistical significance of the fitted linear regression trends were examined using graphical approaches as well as the standards statistical test that include the use of Mann-Kendall Rank Statistics. Similar methods have been adopted in many studies in Africa and the world at large [6] [20] [22] [24] [38] [39] [40].

A linear regression trend was investigated by examining the relationship between time $(\mathrm{T})$ and the variable of interest $(\mathrm{X})$, in this case rainfall, using the following equation

$$
Y(t)=c+b X(t)
$$

$X(t)$ is the individual observed seasonal rainfall/temperature during the baseline period 1960-1990, while $Y(t)$ are corresponding values simulated by the individual CORDEX models over the period 1961-1990, $\mathrm{c}$ and b are normally the intercept and gradient (slope) of the regression equation. The slope indicates the average rate of change in the dependent variable in each year of the given time period. A positive/negative slope shows an increasing/decreasing trend respectively. The limitation of this method is that it assumes that all linkages between observed and CORDEX models generated models are linear, and the distributions of the observed and predicted records are normal.

For non-normal data the study included nonparametric tests namely the Mann-Kendall rank statistics method was used. In the Mann-Kendall analysis data is ranked after being placed in time sequential order. The time series values (X1, X2, X3, X4 .., Xn) where $\mathrm{X}$ in this case represents rainfall are replaced by their relative ranks ( $\mathrm{R} 1, \mathrm{R} 2, \mathrm{R} 3, \mathrm{R} 4 \ldots, \mathrm{Rn}$ ) (starting from the lowest value up to $\mathrm{n})$. The relative magnitudes of sample data is compared rather than the data values themselves [41] [42] [43]. The equation used is as follows, where $\mathrm{S}$ is the Kendall score given a dataset $\mathrm{R}$ with a sample size of $\mathrm{n}$ values. The Kendall statistics $\mathrm{s}$ is given in Equation (2) below based on Kendall, 1938; 1945; 1948

$$
S=\sum_{i=1}^{n-1}\left[\sum_{j=i+1}^{n} \operatorname{sgn}\left(R_{i}-R_{l}\right)\right]
$$

The observed trend is significant if s values in Equation (2) have significance levels equal or less than 0.5 . The ensemble model data was used in this study to compute the correlation value $r$ and linear trend lines for each pixel for the individual seasons. The results for both correlation coefficient $r$ value and the slope were mapped for each pixel and season.

The results from the assessment of Model Skill in Simulating Observed Climate for the various seasons determined the models and seasons that were projected into the future using CORDEX RCA4.5 models. The three sub-periods 
used in the projections included the sub-periods up to 2030 (sub-period 1), up to 2050 (sub-period 2), and up to 2070 (sub-period 3).

\section{Results and Discussion}

The results from model verification and climate change projections with CORDEX RCA4.5 models are independently highlighted in the following sections.

\subsection{Model Verification of the CORDEX (RCMs)}

The annual cycle of Gu (AMJ) and Deyr (SON) season rainfall for the baseline period 1960-90 from gridded CHIRPS observations and CORDEX RCMs simulated outputs were compared the study area in order to determine the best ensemble models that can be used for the future climate change rainfall projections. Future projections of temperature were undertaken for all the four standard seasons of the year. Figure 1(a) and Figure 1(b) illustrate the performance of CORDEX RCMs in simulating annual rainfall and temperature cycles over the study area as compared to the CHIRPS data. All of the RCMs capture fairly well the rainfall seasonality in Lower Jubba. Figure 1(a) shows that the north-south rainfall pattern follows the migration of the ITCZ, with associated locations of maximum rainfall being depicted fairly well by the ensemble model. For the study area, the ensemble mean results were found to simulate fairly well the annual rainfall cycle when compared to individual RCM models.

In general, the study revealed some fairly good agreement between annual rainfall cycle simulated by ensemble of CORDEX RCMs and the CHIRPS data. The most notable shortcoming in most individual RCMs is the early peak and overestimation of the mean monthly rainfall particularly in the Deyr season (Figure 1(a)). Studies have shown that GCMs tend to overestimate rainfall in the Horn of Africa region during October to December season [2] [44].

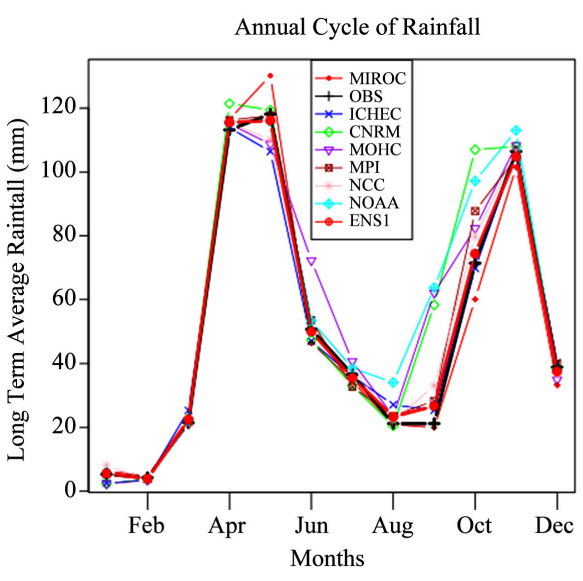

(a)

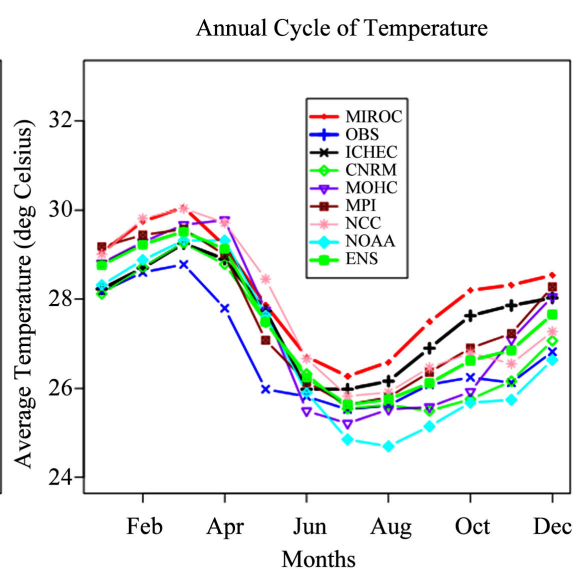

(b)

Figure 1. Graph shows the performance of the different models and the Ensemble model (ENS) in comparison to the observed data (model data: downscaled CORDEX data) for rainfall (a) and temperature (b). 
IPCC reports have indicated limitation in the extent of skilful rainfall projection due to the nonlinear and chaotic nature of the climate system [2].

Results from the study showed that the ensemble models closely reproduced realistic representation of the observed climate features. Figure 1 (b) shows the performance of CORDEX RCMs in simulating the mean surface temperature over Jubaland compared to the observed temperature data. The ensemble model seems to overestimate temperature when compared to the observed data during the hot months of Jan-April while underestimate during July to December, Figure 1 (b).

The results from the study indicated that the multi-model ensembles outperformed the individual RCM model as shown in Figure 2(a) and Figure 2(b). All of the RCMs however captured fairly well the rainfall seasonality in Lower Jubba, though significant biases can be found in individual models depending on the seasons as seen in Figure 2(a). The model bias for precipitation in each individual model varies from month to month. NOAA, CNRM and MPI and overestimated the rainfall data between August and November while MIROC underestimates the rainfall data in the same period.

Figure 2(b) also showed variation in performance of the RCMs from month to month even with the temperature data. ICHEC underestimated the temperatures between January and June, while NOAA underestimated the data between July and December. MOCH and NCC overestimated the data in April. Similar results are from some previous studies for the Multi-model ensemble projections [2] [34] [35] [36].

It observed from the examination of the skill of the individual CORDEX models and ensemble models simulation observed CHIRPS and GEOCLIM data over the period 1961-1990 best during Gu (AMJ) season. Thus projection of future rainfall scenarios was undertaken for only the Gu (AMJ) season. The projections undertaken for temperature were observed for all seasons.

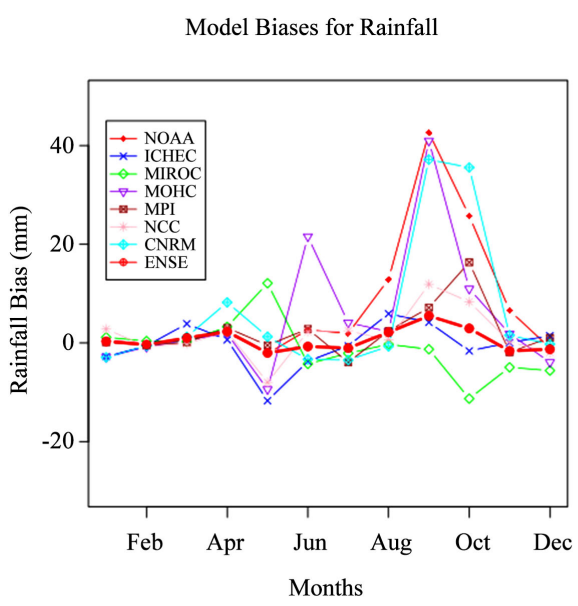

(a)

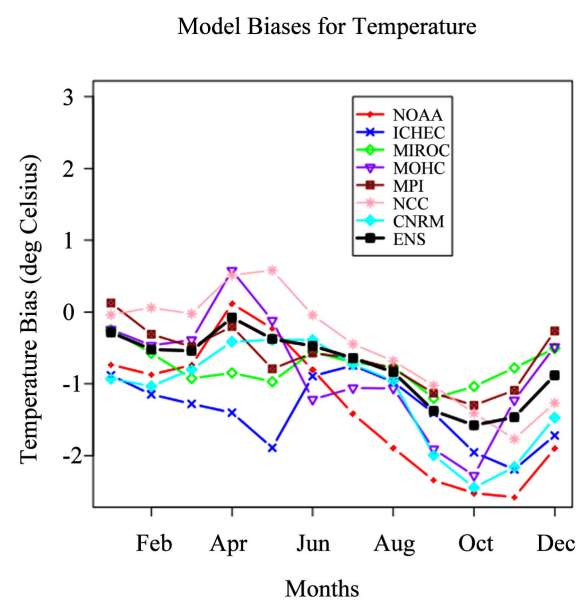

(b)

Figure 2. Showing model bias, calculated by subtracting observed (a) rainfall and (b) temperature data from each model. 
It observed from the examination of the skill of the individual CORDEX models and ensemble models simulation observed CHIRPS and GEOCLIM data over the period 1961-1990 best during Gu (AMJ) season. Thus projection of future rainfall scenarios was undertaken for only the Gu (AMJ) season. The projections undertaken for temperature were observed for all seasons.

\subsection{Results from Future Projections for Rainfall and Temperature}

The results for future projections of rainfall and temperature with the CORDEX RCMs are given below for IPCC sub periods of 2030, 2050 and 2070.

\subsubsection{Rainfall Projections}

The simulations of rainfall concentrated on the Gu (April-June) season, where most models showed more realistic simulations of rainfall. The geographical distribution exhibits notable spatial variability in rainfall over Lower Jubba. Badhaadhe district towards the southern coast exhibits the highest amount of rainfall as seen in Table 1. The southern costal region shows the highest projected amount of rainfall in Lower Jubba throughout all three sub-periods as was seen with the historical data published [20].

The patterns of the projected changes in seasonal ensemble mean Gu rainfall for the three sub-periods namely 2030, 2050 and 2070 showed significant variations in the magnitude of the projected seasonal rainfall from place to place, season, sub-periods and scenarios.

There is a general increase in rainfall in Lower Jubba from 2030 to 2070. The projected rainfall is however not homogeneous throughout the region with the inland region receiving the least amount of rainfall. Similar results are reported in the Somali NAPA which shows an increase in rainfall in 2050 and 2080 [45]. This is also supported by IPCC studies that project an increase in MAM rainfall in 2050-2100 in most parts of Eastern Africa [2]. North eastern Kenya bordering Lower Jubba is projected to receive an increase in rainfall of $40 \%$ relative to the baseline period (1981-2010) by 2100 during its long rain season [46]. Table 1 shows the range of seasonal precipitation from the projected ensemble data for $\mathrm{Gu}$, averaged over the districts in Jubaland, with RCP4.5 scenario for the three sub-periods 2030, 2050 and 2070.

The observed trends of the temporal evolution of the projected precipitation over this region are shown in Figures 3(a)-(c). The results show a decreasing trend for the first sub-period Figure 3(a), followed by an increasing trend for the second and third sub-periods Figure 3(b) and Figure 3(c). The trends are however not statistically significant at a $95 \%$ confidence level. Despite being statistically insignificant the results are similar to those of studies over the region [1] [2] [47]. For Africa, IPCC projects that almost all countries except South Africa will probably experience a significant reduction in precipitation until 2050 which then increases significantly between 2050 and 2100 [2] corroborating the results displayed in Figures 3(a)-(c). The averaged mean water vapor, evaporation 
Table 1. Projected ensemble mean seasonal precipitation for Gu (APJ) rainfall minimum/maximum values in over districts in Lower Jubba for the RCP 4.5.

\begin{tabular}{cccccccc}
\hline & \multicolumn{8}{c}{ Rainfall $(\mathrm{mm})$} \\
\cline { 2 - 8 } District & \multicolumn{2}{c}{2030} & \multicolumn{2}{c}{2050} & \multicolumn{2}{c}{2070} \\
\cline { 2 - 8 } & Min & Max & Min & Max & Min & Max \\
\hline Badhaadhe & 191 & 445 & 209 & 471 & 225 & 498 \\
Afmadow & 180 & 353 & 199 & 368 & 189 & 395 \\
Jamaame & 234 & 337 & 250 & 351 & 284 & 383 \\
Kismaayo & 203 & 310 & 225 & 330 & 260 & 358 \\
\hline
\end{tabular}

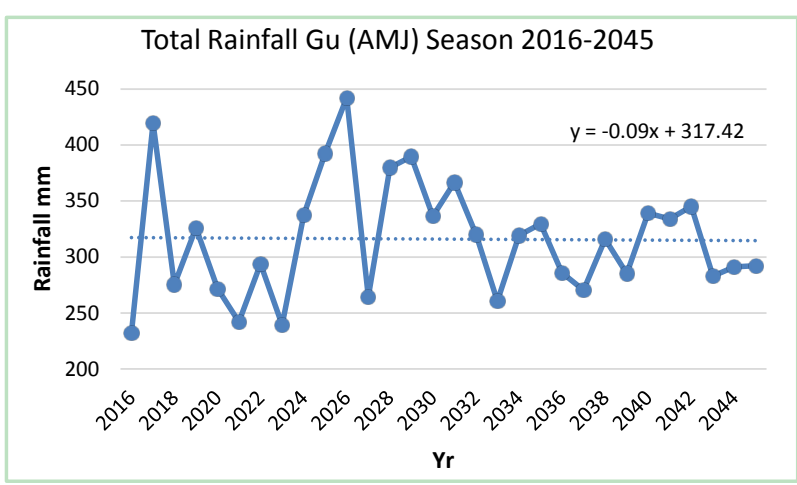

(a)

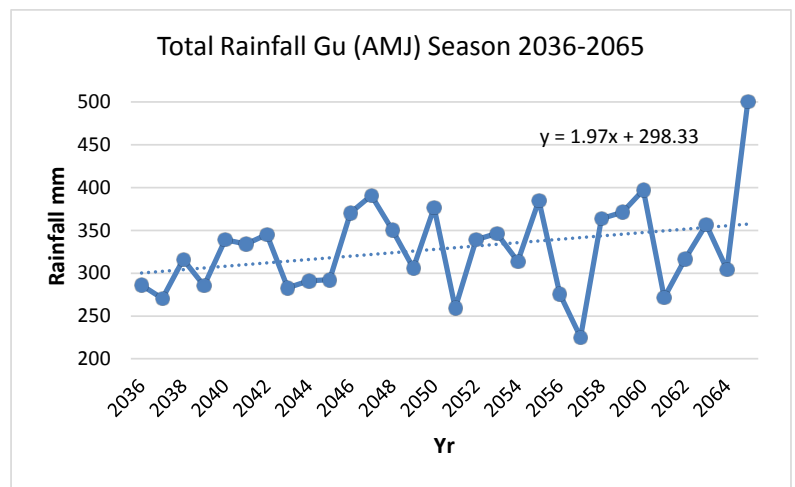

(b)

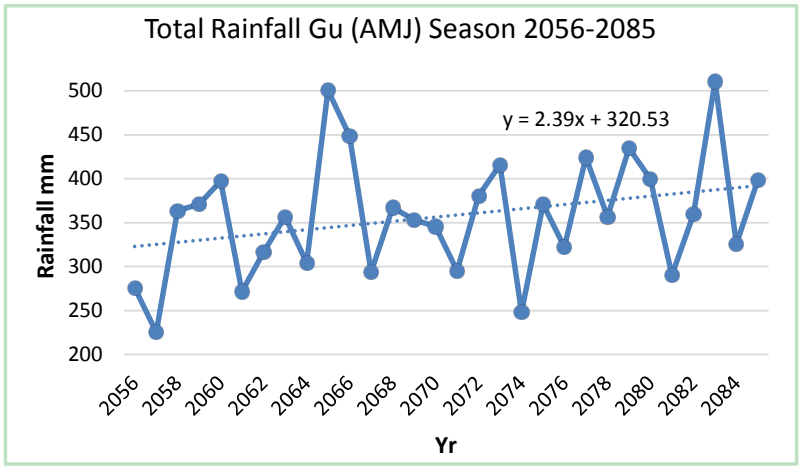

(c)

Figure 3. Total seasonal rainfall during the gu rainfall season in lower Jubba in (a) 2016-2045; (b) 2026-2065; and (c) 2056-2085. 
and precipitation are projected to increase globally by 2100 [1] [2]. The use of climate change knowledge, particularly when mainstreamed into planned policies and poverty reduction strategies can provide a starting point for the identification of climate risks at a district, regional and national level.

The projected rainfall further shows dominant dry and wet phases of the $\mathrm{Gu}$ season in the future (Figure 4), which calls for sustained investment in early warning mechanisms, and water management systems. The spatial representation of the projected rainfall trends showed no homogenous patterns throughout the three study sub periods. While some areas in Lower Jubba are projected to have general decrease in rainfall during the long rain season, other areas were projected to have a general increase in rainfall (Table 2). General increasing trend was however seen throughout Lower Jubba, with different magnitude of the changes.

Details of the pattern in the trend in each district can be seen in Table 2. Although the projected rainfall trends were still not statistically significant, the complexity of the observed characteristics of the changes continues to call for further studies and tailored mitigation and adaptation strategies over the region of study.

Table 2. Summary of Projected Range of Rainfall Trends in Lower Jubba.

\begin{tabular}{|c|c|c|c|c|c|c|}
\hline \multirow{3}{*}{ District } & \multicolumn{6}{|c|}{ Projected Rainfall Trend (mm/decade) } \\
\hline & \multicolumn{2}{|c|}{2030} & \multicolumn{2}{|c|}{2050} & \multicolumn{2}{|c|}{2070} \\
\hline & Min & $\operatorname{Max}$ & Min & $\operatorname{Max}$ & Min & $\operatorname{Max}$ \\
\hline Badhaadhe & 4 & 10 & 10 & 23 & 7 & 33 \\
\hline Afmadow & -1 & 8 & 5 & 18 & 6 & 24 \\
\hline Jamaame & -3 & -1 & 18 & 23 & 25 & 29 \\
\hline Kismaayo & -2 & 9 & 11 & 20 & 8 & 28 \\
\hline
\end{tabular}

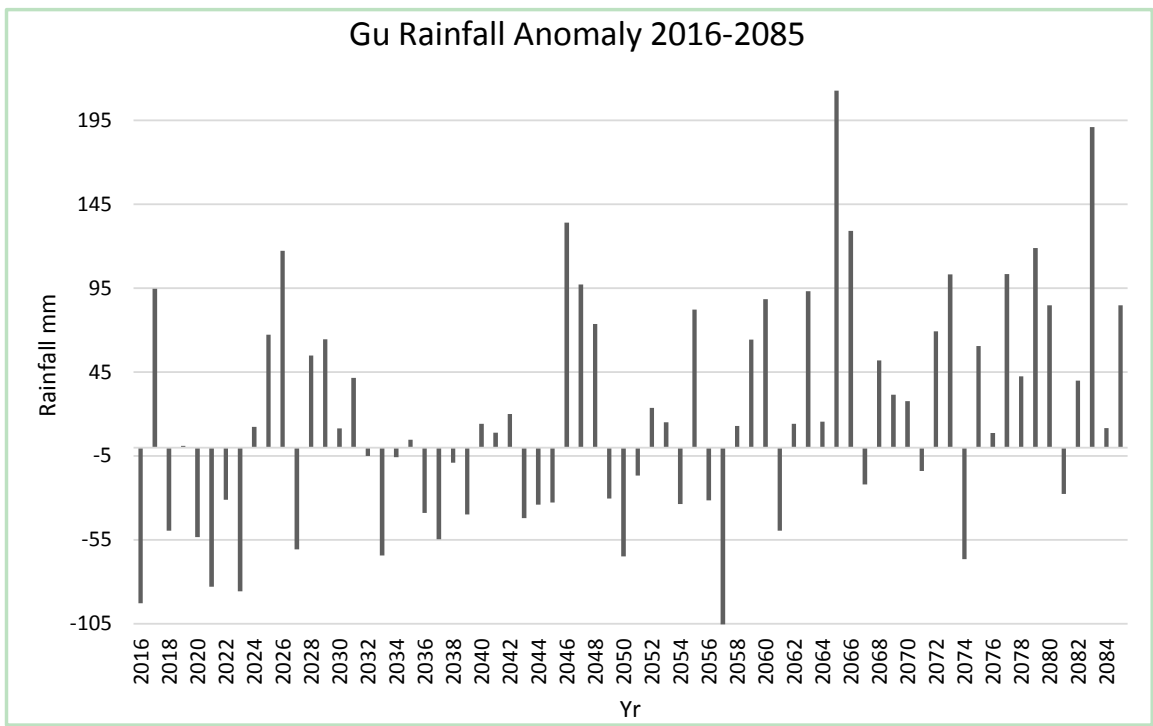

Figure 4. Rainfall anomalies (2016-2085). 
Individual rainfall time series shown in Figure 5 further indicate general dominance of depressed rainfall during the sub period ending in 2030, followed with dominance of positive rainfall anomalies during the last two sub-periods ending in 2050 and 2070. These results signify the need for investment in early warning mechanisms in Lower Jubba. Results on Lower Jubba are similar to projected results for Africa, where the impacts of climate change will be exacerbated by widespread poverty, diseases and high population growth rates, which would intensify the demand for food, water and livestock [47] [48].

The projected recurrence of depressed rainfall for the near future is significant for a country that is already highly vulnerable with high poverty levels across multiple dimensions [49]. Somalia is already experiencing food insecurity, the implication of a further risk to food and water security could pause a threat on security in a struggle for available resources. Furthermore, results from this study have shown that communities in Lower Jubba revert to charcoal production when their livelihoods are threatened, the impact of which is forest degradation. The recurrence of extreme below normal rainfall often associated with drought is also evident, given the communities use of charcoal as an adaptation strategy, an increase in deforestation and degradation can be expected. The projected precipitation presented in this study call for urgency in finding short and mid-term solutions.

The increase in above average rainfall associated with floods as seen in Figure 4 by in sub-period 2 (2050) is also consistent with Tierney, et al. and IPCC that projects increased precipitation in Africa generally during the same period [1] [2] [47].

The magnitude of the extreme above and below average rainfall for the projected future is not the same as seen in Figure 4. Similar results in the bordering regions in Kenya, project an increase in intensity of rainfall, and extreme rainfall events [46].

\subsubsection{Temperature Projections}

The spatial pattern of the projected seasonal ensemble mean surface temperature based on the RCMs are shown for the three sub-periods namely 2030, 2050 and 2070 relative to the baseline period showed general warming at most locations over the three sub periods ending in 2030, 2050 and 2070. Results however show that projected change in temperature will vary from season to season and district to district. Like the observed GISTEMP data [20], the average temperature seems to increase towards the southern costal band in all seasons, possibly due to influence by Indian Ocean [50]. The ensemble models however seemed to overestimate the temperature in JJA which according to the observed data [20] should register the lowest temperature.

Results from the temperature time series (Figure 6) show an increasing temperatures in both the near to long term future. This is in line with global and regional reports that project an increase in the average temperature by 2030 and a further increase by 2050 [2] [24] [25] [44] [51]. Results are statistically significant at 


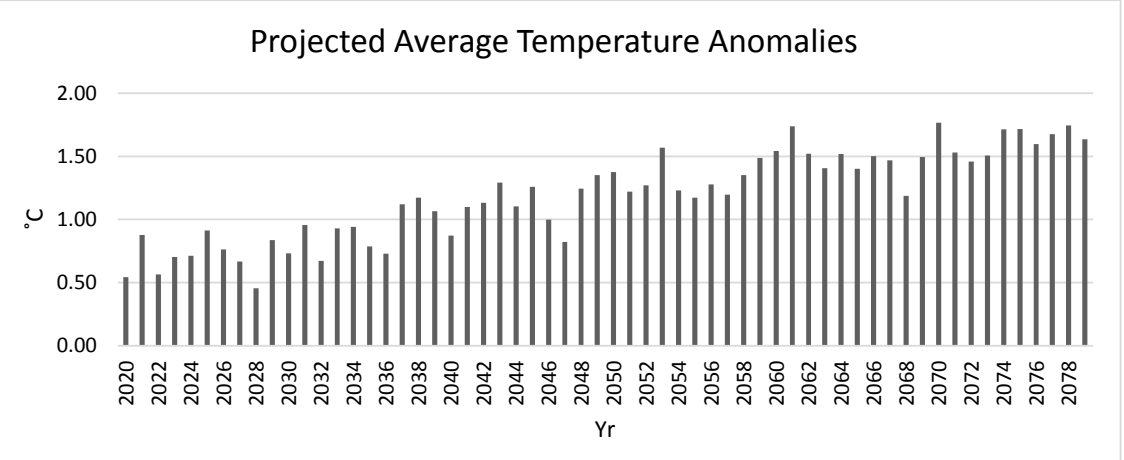

Figure 5. Projected annual average temperature anomalies time series.

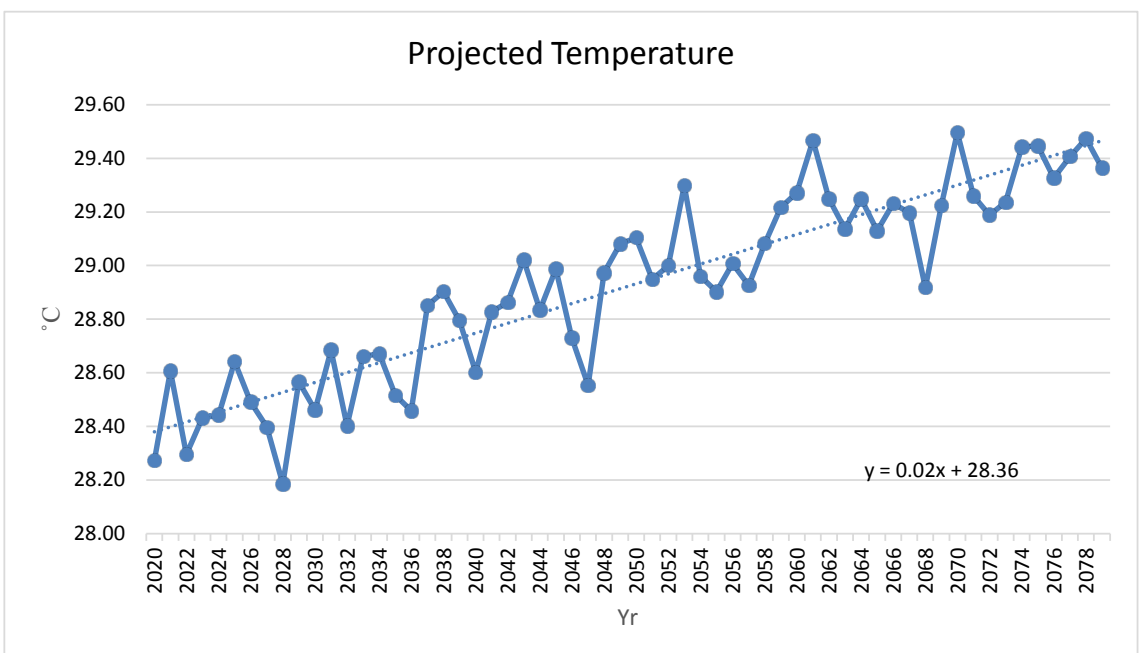

Figure 6. Projected annual average temperature 2020-2079.

95\% confidence level. Changes in temperature and humidity are reportedly linked to increased vector borne diseases and helminthes infections [52]. This will also have far reaching implications on many socio-economic sectors.

Figure 5 shows the anomalies in the projected temperature time series. Results are similar to IPCC [2] reports projecting more hot and fewer cold temperature extremes in most places as global mean temperatures increase in a seasonal time scale. Results showed the rate of increase in temperature by 0.3 to 0.7 degrees by 2035. The unique patterns of the temperature time series is the tendencies for the annual temperature extremes to be generally higher that the preceding years. WMO recent observations have shown such tendencies in the recent years for the annual mean temperature time series.

In general, the projections for Lower Jubba indicated an increase in minimum and maximum temperatures in all seasons in the projection periods 2030, 2050 and 2070. Temperature projections are critical in the development of effective and realistic climate change adaptation and disaster risk reduction strategies. The impact of an increasing temperature would be far reaching for most socio-economic sectors including community safety, water, food, energy, infra- 
structure, among others [26] [53] [54]. The projected temperature would also exacerbate health issues with heat related morbidity and mortality in Africa being projected to increase [26] [27] [53] [54] [55]. Studies have also projected that the geographical distribution of disease prone areas like Malaria will increase as climatic conditions change, creating more conducive conditions for new diseases to breed in areas that were previously disease free [53] [55] [56] [57].

\section{Conclusions}

Projected rainfall change patterns indicated significant increase in high rainfall extremes were exhibited in periods leading up to 2050 and 2070. In the case of temperature, the projections from all the models showed increase in minimum and maximum temperatures in all seasons and sub periods, like being observed temperature projection over other parts of the world. Most of livelihoods and the socio-economic activities in Somalia are dependent on water availability from rainfall. The 2030, 2050 and 2070 projected rainfall and temperature change scenarios show that Somalia future development and livelihoods in future will face increased threats of climate extremes unless effective climate smart adaptation systems form integral components of national development strategies. With the prolonging socio economic stability in the country, the development of the required community based effective climate smart adaptation systems will require support from global and regional partners.

Efforts to achieve food security in Somalia have long been hampered by climate extremes such as floods and drought, as well as civil wars, political volatility, rapid population growth, among other miseries [4] [23] [58] [59]. Most of the socio-economic activities in Lower Jubba are rain dependent. Recurring drought and floods cause acute stress on a developing economy such as that of Lower Jubba. Flooding in Lower Jubba has been linked to RVF outbreaks which in the past has resulted in a ban in the export of livestock from Somalia and led to massive losses for communities and the Somali economy [60] [61] [62]. Rainfall variability, particularly the projected recurrence of below average extremes in the near future would also impact the rate of restoration of disturbed vegetation.

Temperature anomalies indicate recurrences of positive anomalies within all the three projected periods except for OND where some negative anomalies were evident during the first projection period. Seasonal differences, in the observed temperature projections, were quite evident and are major issues that require more studies in order to develop effective and realistic climate change and disaster risk reduction strategies.

Long term adaptation planning by the Jubaland Administration for Lower Jubba must take an integrated approach to both floods and drought for both the near, mid and far future. Investment in early warning systems for daily, monthly, seasonal and inter-annual prediction is critical for any effective adaptation strategy. Timely seasonal forecasts and drought monitoring is essential for drought risk reduction in Lower Jubba where livelihoods are closely intertwined 
with climate variability.

The study further provides some important knowledge on rainfall variability and change over the Lower Jubba region that would contribute to the 6th IPCC assessment report on the state of regional climate change over Africa. The knowledge on the past, present and future rainfall patterns derived from this study is important in the development of any effective disaster risk reduction and climate change strategies of Somalia in supporting sustainable development goals, implementation of the Paris UNFCCC, Sendai disaster risk reduction, among other global, regional, national and community based resilience building frameworks.

\section{Acknowledgements}

IGAD Climate Prediction and Application Centre for the data for climate analysis.

\section{References}

[1] IPCC. (2007) Climate Change 2007: The Physical Science Basis. Contribution of Working Group I. In: Solomon, S., Qin, D., Manning, M., Chen, Z., Marquis, M., Averyt, K.B., Tignor, M. and Miller, H.L., Eds., The Fourth Assessment Report of the Intergovernmental Panel on Climate Change, Cambridge University Press, Cambridge, United Kingdom and New York, NY, 296.

[2] IPCC. (2014) Africa. In: Climate Change 2014: Impacts, Adaptation, and Vulnerability. Part B: Regional Aspects. Contribution of Working Group II to the Fifth Assessment Report of the Intergovernmental Panel on Climate Change, Cambridge University Press, Cambridge, United Kingdom and New York, NY, 1173.

[3] Amissah-Arthur, A. (2003) Targeting Climate Forecasts for Agricultural Applications in Sub-Saharan Africa: Situating Farmers in User-Space. Climatic Change, 58, 73-92. https://doi.org/10.1023/A:1023462613213

[4] Haile, M. (2005) Weather Patterns, Food Security and Humanitarian Response in Sub-Saharan Africa. Philosophical Transactions of the Royal Society B: Biological Sciences, 360, 2169-2182. https://doi.org/10.1098/rstb.2005.1746

[5] Cooper, P., Dimes, J., Rao, K., Shapiro, B., Shifera, B. and Twomlow, S. (2006) Coping Better with Current Climatic Variability in the Rain-Fed Farming Systems of Sub-Saharan Africa: A Dress Rehearsal for Adapting to Future Climate Change? Global Theme on Agroecosystem, 27, 24-35.

[6] Omay, P.O., Ogallo, L.A., Oludhe, C. and Gitau, W. (2016) Temporal and Spatial Characteristics of the June-August Seasonal Rainfall and Temperature over South Sudan. Journal of Meteorology and Related Sciences, 9, 35-49.

[7] Thurow, T.L., Herlocker, D.J. and Elmi, A.A. (1989) Development Projects and Somali Pastoralism. Rangelands, 11, No. 1.

[8] Haydarov, R., Anand, S., Frouws, B., Toure, B., Okiror, S. and Bhui, B.R. (2016) Evidence-Based Engagement of the Somali Pastoralists of the Horn of Africa in Polio Immunization: Overview of Tracking, Cross-Border, Operations, and Communication Strategies. Global Health Communications, 2, 11-18. https://doi.org/10.1080/23762004.2016.1205890

[9] EM-DAT. (2018) The International Disaster Database. http://www.emdat.be/ 
[10] UN OCHA. (2017) Horn of Africa: Humanitarian Impacts of Drought. https://reliefweb.int/report/somalia/horn-africa-humanitarian-impacts-drought-iss ue-11-3-november-2017

[11] Jones, P.G. and Thornton, P.K. (2003) The Potential Impacts of Climate Change on Maize Production in Africa and Latin America in 2055. Global Environmental Change, 13, 51-59. https://doi.org/10.1016/S0959-3780(02)00090-0

[12] Schmidhuber, J. and Tubiello, F.N. (2007) Global Food Security under Climate Change. Proceedings of the National Academy of Sciences of the United States of America, 104, 19703-19708. https://doi.org/10.1073/pnas.0701976104

[13] Challinor, A., Wheeler, T., Garforth, C., Craufurd, P. and Kassam, A. (2007) Assessing the Vulnerability of Food Crop Systems in Africa to Climate Change. Climatic Change, 83, 381-399. https://doi.org/10.1007/s10584-007-9249-0

[14] Lobell, D.B., Burke, M.B., Tebaldi, C., Mastrandrea, M.D., Falcon, W.P. and Naylor, R.L. (2008) Prioritizing Climate Change Adaptation Needs for Food Security in 2030. Science, 319, 607. https://doi.org/10.1126/science.1152339

[15] Brown, M.E. and Funk, C.C. (2008) Food Security under Climate Change. National Aeronautics and Space Administration, Paper 131.

https://doi.org/10.1126/science.1154102

[16] IUCN (2006) Country Environmental Profile for Somalia. The European Commission Somalia Operations Office, Nairobi.

https://europa.eu/capacity4dev/file/33006/download?token=OUsVfuq

[17] Jamal, A.R. (2015) Identifying Causes of State Failure: The Case of Somalia. University of Konstanz, Konstanz.

[18] Maystadt, J.-F. and Ecker, O. (2014) Extreme Weather and Civil War: Does Drought Fuel Conflict in Somalia through Livestock Price Shocks? American Journal of Agricultural Economics, 96, 1157-1182. https://doi.org/10.1093/ajae/aau010

[19] AMISOM (2016) African Union Mission in Somalia. http://amisom-au.org/wp-content/uploads/2013/11/Sector-II-Kismayo.pdf

[20] Ogallo, L.A., Ouma, G. and Omondi, P. (2017) Changes in Past and Present Rainfall and Surface Temperature over Lower Jubba, Somalia. Journal of Climate Change and Sustainability, 1, 39-52.

[21] Schreck, C.J. and Semazzi, F.H. (2004) Variability of the Recent Climate of Eastern Africa. International Journal of Climatology, 24, 681-701. https://doi.org/10.1002/joc.1019

[22] Omondi, P.A., Ogallo, L.A. and Okoola, R.A. (2009) Decadal Rainfall Variability Modes in Observed Rainfall Records over East Africa and Their Predictability using Sea Surface Temperature. Journal of Meteorology and Related Sciences, 3, 37-54.

[23] Omondi, P.A., Awange, J.L., Forootan, E., Ogallo, L.A., Barakiza, R., Girmaw, G.B. and Komutunga, E. (2014) Changes in Temperature and Precipitation Extremes over the Greater Horn of Africa Region from 1961 to 2010. International Journal of Climatology, 34, 1262-1277. https://doi.org/10.1002/joc.3763

[24] King'uyu, S.M., Ogallo, L.A. and Anyamba, E.K. (2000) Recent Trends of Minimum and Maximum Surface Temperatures over Eastern Africa. Journal of Climate, 13, 2876-2887. https://doi.org/10.1175/1520-0442(2000)013<2876:RTOMAM>2.0.CO;2

[25] Easterling, D.R., Horton, B., Jones, P.D., Peterson, T.C., Karl, T.R., Parker, D.E. and Folland, C.K. (2009) Maximum and Minimum Temperature Trends for the Globe. Science, 277, 364-367.

[26] Patz, J.A., Epstein, P.R., Burke, T.A. and Balbus, J.M. (1996) Global Climate Change 
and Emerging Infectious Diseases. Journal of the American Medical Association, 275, 217-223. https://doi.org/10.1001/jama.1996.03530270057032

[27] WHO (2003) Climate Change and Human Health: Risks and Responses. World Health Organization, Geneva.

[28] GeoCLIM (2016) GHC. Climate Hazard Group. http://chg.geog.ucsb.edu/tools/geoclim/

[29] ICPAC (2016) IGAD Climate Prediction and Application Centre. http://ftp.chg.ucsb.edu/pub/org/chg/products/GeoCLIM/Geoclim_archives/

[30] Taylor, K.E., Stouffer, R.J. and Meehl, G.A. (2012) An Overview of CMIP5 and the Experiment Design. American Meteor Society, 93, 485-498. https://doi.org/10.1175/BAMS-D-11-00094.1

[31] Samuelsson, P., Jones, O.G., Willen, U., Ullrstig, A., Gollvic, S., Hansson, U., Wyser, K., et al. (2011) The Rossby Centre Regional Climate Model RCA3: Model Description and Performance. Tellus $A, 63,4-23$. https://doi.org/10.1111/j.1600-0870.2010.00478.x

[32] Nikulin, G., Jones, C., Giorgi, F., Asrar, G., Chner, M.B., Cerezo-Mota, R. and Fernandez, J. (2012) Precipitation Climatology in an Ensemble of CORDEX-Africa Regional Climate Simulations. Journal of Climate, 25, 6057-6078. https://doi.org/10.1175/JCLI-D-11-00375.1

[33] Endris, H.S., Omondi, P., Jain, S., Lennarda, C., Hewitson, B., Chang'ad, L. and Tazalika, L. (2013) Assessment of the Performance of CORDEX Regional Climate Models in Simulating East African Rainfall. Journal of Climate, 26, 8453-8475. https://doi.org/10.1175/JCLI-D-12-00708.1

[34] Gbobaniyi, E., Sarr, A., Sylla, M.B., Diallo, I., Lennard, C., Dosio, A. and Lamptey, B. (2013) Climatology, Annual Cycle and Interannual Variability of Precipitation and Temperature in CORDEX Simulations over West Africa. International Journal of Climatology, 34, 2241-2257.

[35] Kalognomou, E.-A., Lennard, C., Shongwe, M., Pinto, I., Favre, A., Kent, M., Büchner, M., et al. (2013) A Diagnostic Evaluation of Precipitation in CORDEX Models over Southern Africa. American Meteorological Society, 9477. https://doi.org/10.1175/JCLI-D-12-00703.1

[36] Buontempo, C., Camilla, M., Richard, J., Karina, W., Changgui, W. and Carol, M. (2014) An Ensemble Climate Projection for Africa. Climate Dynamics, 44, 2097-2118.

[37] Giorgi, F., Coppola, E., Solmon, F., et al. (2012) RegCM4: Model Description and Preliminary Tests over Multiple CORDEX Domains. Climate Research, 52, 7-29. https://doi.org/10.3354/cr01018

[38] Ogallo, L.A. (1980) Rainfall Variability in Africa. Monthly Weather Review, 107, 1133-1139. https://doi.org/10.1175/1520-0493(1979)107<1133:RVIA >2.0.CO;2

[39] Ogallo, L.A. (1981) Trend of Rainfall in East Africa. Kenya Journal of Science and Technology, 2, 83-90.

[40] Ogallo, L.A., Bessemoulin, P., Ceron, J.-P., Mason, S. and Connor, S.J. (2008) Adapting to Climate Variability and Change: The Climate Outlook Forum Process. WMO, Vol. 57.

[41] Kendall, M.G. (1938) A New Measure of Rank Correlation. Biometrika, 33, 81-93. https://doi.org/10.1093/biomet/30.1-2.81

[42] Kendall, M.G. (1945) The Treatment of Ties in Ranking Problems. Biometrika, 33, 297-298. https://doi.org/10.1093/biomet/33.3.239 
[43] Kendall, M.G. (1948) Rank Correlation Methods. Charles Griffin, London.

[44] Anyah, R.O. and Qiu, W. (2012) Characteristic 20th and 21st Century Precipitation and Temperature Patterns and Changes over the Greater Horn of Africa. International Journal of Climatology, 32, 347-363. https://doi.org/10.1002/joc.2270

[45] FGS (2013) National Adaptation Programme for Action on Climate Change. Federal Government of Somalia, Mogadishu.

[46] AEA (2008) Kenya: Climate Screening and Information Exchange for International Development. Prepared by UK Department for International Development (DFID) AEA Group, Harwell. http://www.dewpoint.org.uk/Article.Aspx?ArticleID=901

[47] Tierney, J.E., Ummenhofer, C.C. and deMenocal, P.B. (2015) Past and Future Rainfall in the Horn of Africa. Science Advances, 1, e1500682. https://doi.org/10.1126/sciadv.1500682

[48] Connolly-Boutin, L. and Smit, B. (2016) Climate Change, Food Security, and Livelihoods in Sub-Saharan Africa. Regional Environmental Change, 16, 385-399. https://doi.org/10.1007/s10113-015-0761-x

[49] UNDP (2012) Somalia Human Development Report 2012. United Nations Development Program, Nairobi.

[50] Jaswal, A.K., Virendra, S. and Bhambak, S.R. (2012) Relationship between Sea Surface Temperature and Surface Air Temperature over Arabian Sea, Bay of Bengal and Indian Ocean. Journal of Indian Geophysical Union, 16, 41-53.

[51] Few, R., Seytal, P., McGahey, D., Leavy, J., Budd, J., Assen, M., Bewket, W., et al. (2015) Vulnerability and Adaptation to Climate Change in Semi-Arid Areas in East Africa. ASSAR Working Paper, 111.

[52] Terink, W., Hurkmans, R.T.W.L., Torfs, P.J.J.F. and Uijlenhoet, R. (2010) Evaluation of a Bias Correction Method Applied to Downscaled Precipitation and Temperature Reanalysis Data for the Rhine Basin. Hydrological and Earth System Sciences, 14, 687-703. https://doi.org/10.1002/joc.3650

[53] Patz, J.A., Campbell-Lendrum, D., Holloway, T. and Foley, J.A. (2005) Impact of Regional Climate Change on Human Health Human Health. Nature, 438, 310-317. https://doi.org/10.1038/nature04188

[54] McMichael, A.J., Woodruff, R.E. and Hales, S. (2006) Climate Change and Human Health: Present and Future Risks. The Lancet, 367, 859-869. https://doi.org/10.1016/S0140-6736(06)68079-3

[55] Paaijmansa, K.P., Blanford, S., Bellb, A.S., Blanford, J.I., Read, A.F. and Thomas, M.B. (2010) Influence of Climate on Malaria Transmission Depends on Daily Temperature Variation. PNAS, 107, 15135-15139. https://doi.org/10.1073/pnas.1006422107

[56] Martens, W.J., Niessen, L.W., Rotmans, J., Jatten, T.H. and McMichael, A.J. (1995) Potential Impact of Global Climate Change on Malaria Risk. Environmental Health Perspectives, 103, 458-464. https://doi.org/10.1289/ehp.95103458

[57] Patz, J.A. and Olson, S.H. (2006) Malaria Risk and Temperature: Influences from Global Climate Change and Local Land Use Practices. PNAS, 103, 5635-5636. https://doi.org/10.1073/pnas.0601493103

[58] Indeje, M., Fredrick, S.H. and Ogallo, L.A. (2000) Enso Signals in East African Rainfall Seasons. International Journal of Climatology, 20, 19-46. https://doi.org/10.1002/(SICI)1097-0088(200001)20:1<19::AID-JOC449>3.0.CO;2-0

[59] Sheffield, J., Wood, E.F., Chaney, N., Guan, K., Sadri, S., Yuan, X., Ogallo, L., et al. (2014) A Drought Monitoring and Forecasting System for Sub-Sahara African Wa- 
ter Resources and Food Security. Bulletin of the American Meteorological Society, 95, 861-882. https://doi.org/10.1175/BAMS-D-12-00124.1

[60] Cagnolati, V., Tempia, S. and Abdi, A.M. (2006) Economic Impact of Rift Valley Fever on the Somali Livestock Industry and a Novel Surveillance Approach in Nomadic Pastoral Systems. 11 th International Symposium on Veterinary Epidemiology and Economics, Cairns, August 2006, 551.

[61] Bachorz, B. (2012) Massive Deforestation Risks Turning Somalia. Business Recorder, 20.

https://www.capitalfm.co.ke/news/2012/11/massive-deforestation-risks-turning-so malia-into-desert/

[62] NMG (2012) Charcoal Business Risks Turning Somalia into Desert.

http://www.africareview.com/special-reports/Charcoal-business-risks-turning-Som alia-into-desert/979182-1624152-1525iqkz/index.html 